\title{
An Integrated Approach for Determining Plutonium Mass in Spent Fuel Assemblies with Nondestructive Assay
}

\author{
Martyn T. Swinhoe, Stephen J. Tobin, Mike L. Fensin and Howard O. Menlove
}

Abstract- There are a variety of reasons for quantifying plutonium $(\mathrm{Pu})$ in spent fuel. Below, five motivations are listed:

(1) To verify the Pu content of spent fuel without depending on unverified information from the facility, as requested by the IAEA ("independent verification"). New spent fuel measurement techniques have the potential to allow the IAEA to recover continuity of knowledge and to better detect diversion.

(2) To assure regulators that all of the nuclear material of interest leaving a nuclear facility actually arrives at another nuclear facility ("shipper/receiver"). Given the large stockpile of nuclear fuel at reactor sites around the world, it is clear that in the coming decades, spent fuel will need to be moved to either reprocessing facilities or storage sites. Safeguarding this transportation is of significant interest.

(3) To quantify the $\mathrm{Pu}$ in spent fuel that is not considered "self-protecting." Fuel is considered self-protecting by some regulatory bodies when the dose that the fuel emits is above a given level. If the fuel is not self-protecting, then the $P u$ content of the fuel needs to be determined and the Pu mass recorded in the facility's accounting system. This subject area is of particular interest to facilities that have research-reactor spent fuel or old light-water reactor (LWR) fuel. It is also of interest to regulators considering changing the level at which fuel is considered selfprotecting.

(4) To determine the input accountability value at an electrochemical processing facility. It is not expected that an electrochemical reprocessing facility will have an input accountability tank, as is typical in an aqueous reprocessing facility. As such, one possible means of determining the input accountability value is to measure the Pu content in the spent fuel that arrives at the facility.

(5) To fully understand the composition of the fuel in order to efficiently and safely pack spent fuel into a long-term repository. The NDA of spent fuel can be part of a system that cost-effectively meets the burnup credit needs of a repository.

Behind each of these reasons is a regulatory structure with MC\&A requirements. In the case of the IAEA, the accountable quantity is elemental plutonium.

The material in spent fuel (fissile isotopes, fission products, etc.) emits signatures that provide information about the content and history of the fuel. A variety of nondestructive assay (NDA) techniques are available to quantify these signatures. The effort presented in this paper is investigation the capabilities of 12 NDA techniques. For these 12, none is conceptually capable of

The authors are with the Los Alamos National Laboratory, Los Alamos, NM, USA independently determining the $P u$ content in a spent fuel assembly while at the same time being able to detect the diversion of a significant quantity of rods. For this reason the authors are investigating the capability of 12 NDA techniques with the end goal of integrating a few techniques together into a system that is capable of measuring $\mathrm{Pu}$ mass in an assembly.

The work described here is the beginning of what is anticipated to be a five year effort: (1) two years of modeling to select the best technologies, (2) one year fabricating instruments and (3) two years measuring spent fuel. This paper describes the first two years of this work.

In order to cost effectively and robustly model the performance of the 12 NDA techniques, an "assembly library" was created. The library contains the following: (a) A diverse range of PWR spent fuel assemblies (burnup, enrichment, cooling time) similar to that which exists in spent pools today and in the future. (b) Diversion scenarios that capture a range of possible rod removal options. (c) The spatial and isotopic detail needed to accurately quantify the capability of all the NDA techniques so as to enable integration. (It is our intention to make this library available to other researchers in the field for inter-comparison purposes). The performance of each instrument will be quantified for the full assembly library for measurements in three different media: air, water and borated water.

The 12 NDA techniques being researched are the following: Delayed Gamma, Delayed Neutrons, Differential Die-Away, Lead Slowing Down Spectrometer, Neutron Multiplicity, Nuclear Resonance Fluorescence, Passive Prompt Gamma, Passive Neutron Albedo Reactivity, Self-integration Neutron Resonance Densitometry, Total Neutron (Gross Neutron), X-Ray Fluorescence, ${ }^{252} \mathrm{Cf}$ Interrogation with Prompt Neutron Detection.

Index Terms - fissile material, gamma measurement, neutron measurement, plutonium, non-proliferation safeguards

\section{INTRODUCTION}

$T^{H I S}$ There are a variety of reasons for quantifying plutonium $(\mathrm{Pu})$ in spent fuel. Below, five motivations are listed:

(1) To verify the $\mathrm{Pu}$ content of spent fuel without depending on unverified information from the facility, as requested by the IAEA ("independent verification"). New spent fuel measurement techniques have the potential to allow the IAEA to recover continuity of knowledge and to better detect diversion.

(2) To assure regulators that all of the nuclear material of interest leaving a nuclear facility actually arrives at another nuclear facility ("shipper/receiver"). Given the large stockpile of nuclear fuel at reactor sites around the 
world, it is clear that in the coming decades, spent fuel will need to be moved to either reprocessing facilities or storage sites. Safeguarding this transportation is of significant interest.

(3) To quantify the $\mathrm{Pu}$ in spent fuel that is not considered "self-protecting." Fuel is considered self-protecting by some regulatory bodies when the dose that the fuel emits is above a given level. If the fuel is not selfprotecting, then the $\mathrm{Pu}$ content of the fuel needs to be determined and the $\mathrm{Pu}$ mass recorded in the facility's accounting system. This subject area is of particular interest to facilities that have research-reactor spent fuel or old light-water reactor (LWR) fuel. It is also of interest to regulators considering changing the level at which fuel is considered self-protecting.

(4) To determine the input accountability value at an electrochemical processing facility. It is not expected that an electrochemical reprocessing facility will have an input accountability tank, as is typical in an aqueous reprocessing facility. As such, one possible means of determining the input accountability value is to measure the $\mathrm{Pu}$ content in the spent fuel that arrives at the facility.

(5) To fully understand the composition of the fuel in order to efficiently and safely pack spent fuel into a long-term repository. The NDA of spent fuel can be part of a system that cost-effectively meets the burnup credit needs of a repository.

Behind each of these reasons is a regulatory structure with MC\&A requirements. In the case of the IAEA, the accountable quantity is elemental plutonium. Also, the determination of the plutonium $(\mathrm{Pu})$ content in spent fuel by means of nondestructive assay (NDA) was identified in recent safeguards research and development review (Advanced Fuel Cycle Facility Working Group, Enhancement Study of the Safeguard Campaign) as a top priority [1]. The material in spent fuel (fissile isotopes, fission products, etc.) emits signatures that provide information about the content and history of the fuel. A variety of nondestructive assay (NDA) techniques are available to quantify these signatures. The effort presented in this paper is investigation the capabilities of 12 NDA techniques. For these 12, none is conceptually capable of independently determining the Pu content in a spent fuel assembly while at the same time being able to detect the diversion of a significant quantity of rods. For this reason the authors are investigating the capability of 12 NDA techniques with the end goal of integrating a few techniques together into a system that is capable of measuring Pu mass in an assembly.

The research plan to determine $\mathrm{Pu}$ mass in spent fuel that started in early 2009 is nominally a five year effort and is part of the Next Generation Safeguard Initiative [2].

\section{METHODS}

The 12 NDA techniques being pursued are the following: Delayed Gamma [3], Delayed Neutrons [4], Differential DieAway DDT [5], Lead Slowing Down Spectrometer
LSDS[6],[7], Neutron Multiplicity [8], Nuclear Resonance Fluorescence NRF [9], Passive Prompt Gamma [10], Passive Neutron Albedo Reactivity PNAR [10],[11],[12], Selfintegration Neutron Resonance Densitometry SINRD [13],[14] Total Neutron (Gross Neutron) [2], X-Ray Fluorescence [15], ${ }^{252} \mathrm{Cf}$ Interrogation with Prompt Neutron Detection. These techniques vary greatly in maturity and the amount of previous research work carried out. They were selected as having reasonable potential to give a value for the plutonium in a spent fuel assembly - either alone or in combination with another technique. A brief description of each technique can be found in [16] and the references given above describe the techniques in more detail.

\section{APPROACH}

The first stage of this project is to make a simulation study of the performance of all of the selected instruments using MCNPX [17]. In general a balanced approach combining measurements and modeling is desirable. Measurements keep the modeling grounded in reality and modeling gives researchers confidence that the basic physics is understood correctly and allows cost-effective refinement of a concept. However, in the case of determining the Pu mass in spent fuel, there are several reasons to emphasize modeling up front: (1) the need to integrate among techniques, (2) the high cost of measuring spent fuel, (3) the number of viable techniques, and (4) the promise of quantifying simple scaling laws.

In order to determine the composition of the target assemblies, a spent fuel library with a range of representative PWR fuel assemblies has been created using MCNPX/CINDER [18]. This includes typical initial enrichment, burnup and cooling time as well as assemblies from which pins have been removed (diversion cases). Then for each instrument, a Monte Carlo model will be created and the instrument response will be calculated for all of the cases defined in the spent fuel library. In this way we will quantify the performance of each instrument for systematic standardized comparisons between all the instruments.

\section{SPENT FUEL LIBRARY AND TOOLS}

The spent fuel library was based on an infinitely reflected $17 \times 17$ Westinghouse fuel assembly. The cases include $2 \%$, $3 \%, 4 \%$, and $5 \%$ initial enrichment burned to $15,30,45$, and $60 \mathrm{GWd} / \mathrm{tU}$, with cooling times of 1 and 4 weeks, and 1, 2, 5, 20 , and 80 years. There are 64 standard assembly cases with an additional 40 cases representing potential diversions of pins. All the rods in this fuel assembly are in the process of being modeled with high spatial resolution (several cells in the radial direction) and isotopic resolution (fission fragments most notable poisons). These results of this modeling effort are available for interested parties in other laboratories who may wish to test the performance of their measurement techniques on this standard set of materials.

Because of the large number of individual cases, a program was written to automate data transition from the spent fuel 
output files to the fixed source instrument input files. The user interface for diversion scenario creation using the Burnup Automation MCNPX File data Retrieval Tool [19] is shown in Figure 1.

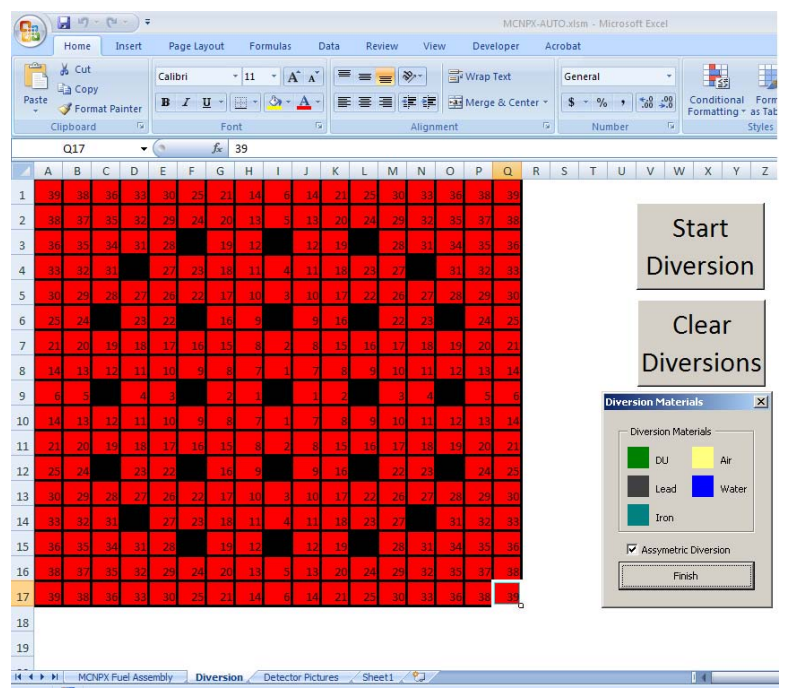

Fig. 1. Creating Diversion Scenarios with the Burnup Automation MCNPX File data Retrieval Tool

\section{INSTRUMENTS}

We are in the process of creating models for the different instruments that would be used for each of the techniques. Some examples of the conceptual intruments are shown in Figures 2 and 3. In each case the model tries to incorporate the practical details of the system. For example if there is any structure of a neutron generator that would affect the neutron transport, then it is included.

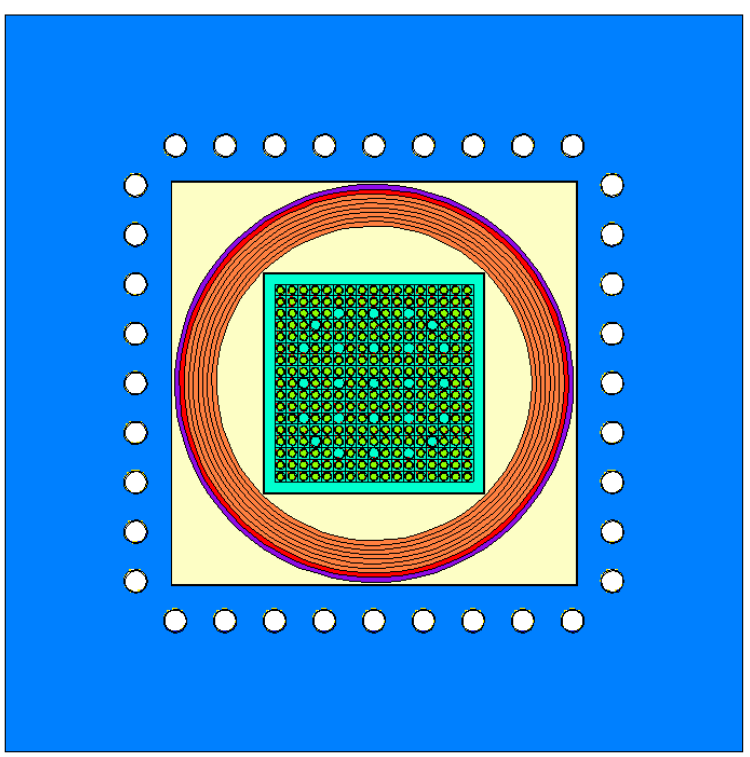

Fig. 2. Delayed Neutron Detector

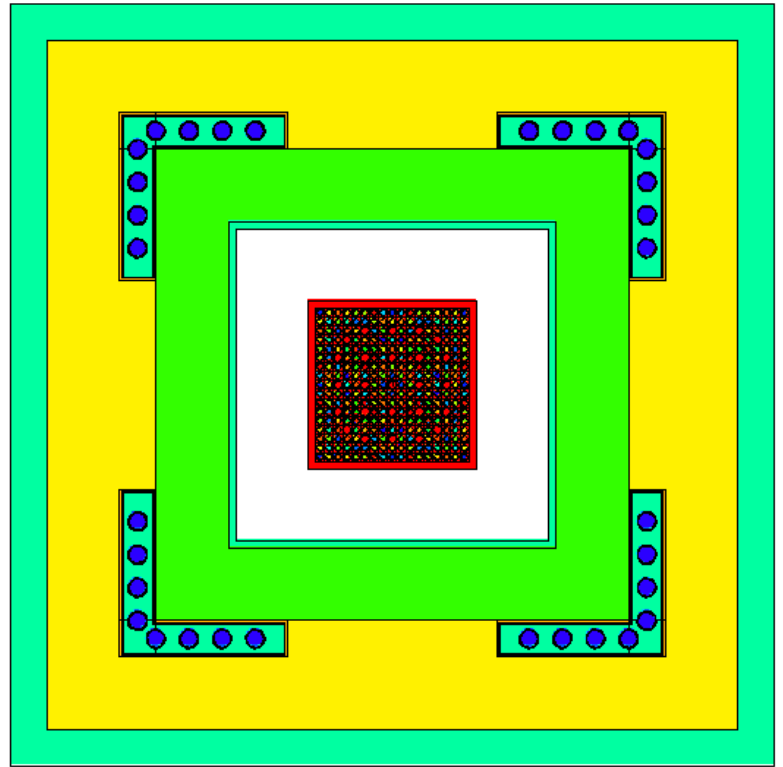

Fig. 3. Conceptual Differential Die-away Detector

For the active techniques the status and likely developments of the neutron and gamma sources is taken into account in order to determine the performance of the instrument

\section{COMBINING TeChNIQUeS}

The following discussion is not intended to be a comprehensive discussion of how various techniques could be combined. It gives some examples of how the different instruments could be combined.

- Delayed gamma measurements can give the relative amount of ${ }^{235} \mathrm{U},{ }^{239} \mathrm{Pu}$ and ${ }^{241} \mathrm{Pu}$. This would help any of the techniques measuring fissile content such as delayed neutron, DDT, coincidence counting and PNAR since these techniques need to separate the relative contribution from $\mathrm{Pu}$ and $\mathrm{U}$ isotopes to the total fissile content. Delayed gamma measurement could work particularly well with delayed neutron and DDT since an active interrogation system already exists.

- Delayed neutron and DDT complement each other in that both measure fissile content but the delayed neutrons measurements emphasize the presence of ${ }^{235} \mathrm{U}$ while DDT emphasizes the presence of fissile $\mathrm{Pu}$. It should be possible to unfold the $\mathrm{U}$ from the $\mathrm{Pu}$ in fissile content. Furthermore, both techniques need a strong neutron generator. Assuming ${ }^{235} \mathrm{U}$ and $\mathrm{Pu}_{\text {effective }}$ can be determined by combining both these techniques, determining elemental $\mathrm{Pu}$ will require knowledge about the relative isotopic concentration among the $\mathrm{Pu}$ isotopes that can be determined from burnup code results or from an extensive experimental data base or NRF.

- LSDS, like the fissile content based techniques, needs burnup information in order to determine elemental $\mathrm{Pu}$ from knowledge of ${ }^{235} \mathrm{U},{ }^{239} \mathrm{Pu}$ and ${ }^{241} \mathrm{Pu}$. The total 
neutron counting for burnup determination is already built into the LSDS system. The ability to detect both fissile $\mathrm{U}$ and $\mathrm{Pu}$ should reduce the uncertainty in the burnup codes involving the amount of the initial enrichment and irradiation history.

- An efficient ${ }^{3} \mathrm{He}$ tube based PNAR system can do coincidence analysis at two different neutron energies (above $1 \mathrm{eV}$ and for the entire energy spectrum). Since the coincidence analysis can quantify multiplication and this is a function of neutron energy, it is likely that additional information about the fissile content can be unfolded from the coincidence counting analysis. PNAR, like LSDS and the fissile content based techniques, needs burnup and cooling time information in order to determine elemental $\mathrm{Pu}$.

- $\quad \mathrm{NRF}$, if it were able to measure the ratio of all the $\mathrm{Pu}$ isotopes, would replace the need for burnup codes and cooling time information for the fissile content and LSDS techniques. Since the NRF technique is unproven at this time, the role of burnup codes and cooling time information was stated as required above. Furthermore, if the NRF technique performs favorably, it would be possible to change the interrogating source for both the delayed neutron and DDT techniques to use photofission instead of neutron induced fission. However, penetrability of the photons may be an issue for fuel assemblies.

- Passive Gammas may be used to quantify the relative number of fissions from ${ }^{235} \mathrm{U}$ as compared to ${ }^{239} \mathrm{Pu}$ during irradiation for the first few decades after leaving the reactor provided the ${ }^{154} \mathrm{Eu}$ is strong enough. However, the initial $U$ enrichment will be needed to interpret the fission product ratios. This information is of value to the techniques measuring fissile content such as delayed neutron, DDT, coincidence counting and PNAR.

- $\quad$ SINRD would help any of the techniques measuring fissile content such as delayed neutron, DDT, coincidence counting and PNAR. Combining SINRD with burnup information from total neutron counting would allow the total fissile content from $\mathrm{Pu}$ to be determined $\left({ }^{239} \mathrm{Pu}+{ }^{241} \mathrm{Pu}\right)$.

- $\quad \mathrm{XRF}$ would be of value to the techniques measuring fissile content such as delayed neutron, DDT, coincidence counting and PNAR. Knowledge of the $\mathrm{Pu}$ to $\mathrm{U}$ ratio in the edge of a rod should assist in deconvolving the $\mathrm{Pu}$ fissile content from the $\mathrm{U}$ fissile content.

\section{SUMmary AND CONCLUSIONS}

This paper has presented the outline of a project to make a systematic evaluation of the methods to measure the plutonium content of spent fuel assemblies. The project consists of an evaluation of the methods using modeling, followed by construction and practical testing of an optimized instrument using a combination of methods. The modeling phase is well under way. A library of representative PWR assemblies has been created using MCNPX-CINDER. This library represents the isotopic composition of the assemblies with a range of initial enrichment, burnup and cooling time. The library provides a description of the target assemblies to be measured and also includes assemblies with various pins replaced to represent diversion scenarios. This library is available for the use of other interested parties. The models of a number of instruments have been produced and the calculated performance is being presented at a number of conferences. Any collaboration in this stage of the project, such as calculations made with the standard library and different instruments or variants of the above instruments would significantly enhance its value. The calculations for all instruments are proceeding and the next step is to determine an optimum combination of techniques for experimental testing. The testing would ideally be done on fuel that has well known plutonium content and/or the possibility for pin removal. Such opportunities are limited and cooperation with suitable facilities is very desirable also in the experimental phase.

\section{ACKNOWLEDGMENT}

The authors thank the Department of Energy - National Nuclear Security Administration (241, 242 and 243) and the Department of Energy - Office of Nuclear Energy for funding this research during the past two years. The technical efforts of the following individuals are also appreciated: numerous subject matter experts and the following students: Sandra De La Cruz, Brian Quiter, Akshayan Rajasingum, Nathan Sandoval and Scott Thompson.

\section{REFERENCES}

[1] Smith L.E., "GNEP Safeguards Enhancement Study: FY08 Interim Report," Pacific Northwest National Laboratory Document, PNNL17431 (2008).

[2] A. Scheinman, Next Generation Safeguards Initiative Inaugural

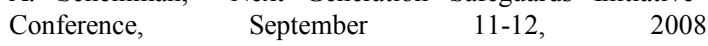
http://nnsa.energy.gov/nuclear_nonproliferation $/ 2147 . \mathrm{htm}$

[3] Reilly D.T., "Passive Nondestructive Assay of Nuclear Materials," Office of Nuclear Regulatory Research, NUREG/CR-5550, Los Alamos National Laboratory Document LA-UR-90-732 (1990).

[4] Rinard P.M., "Application Guide to Shufflers," Los Alamos National Laboratory Report, LA-13819-MS (2001).

[5] Caldwell J.T. and Kunz W.E., "Experimental Evaluation of the Differential Die-Away Pulsed-Neutron Technique for the Fissile Assay of Hot Irradiated Fuel Waste," ANS topical meeting on treatment and handling of radioactive waste, Richmond Washington, USA, (1982).

[6] Ressler J.J., Smith L.E., Anderson K., "Lead Slowing Down Spectroscopy for Direct Pu Mass Measurements," $8^{\text {th }}$ International Conference on Facility Operations - Safeguards Interface, March $30-$ April 4, 2008, Portland.

[7] Abdurrahman N.M. et al., "Spent-Fuel Assay Performance and Monte Carlo Analysis of the Rensselaer Slowing-Down-Time Spectrometer," Nuclear Science and Engineering, 115, 279-296 (1993).

[8] Ensslin N. et al., "Application Guide to Neutron Multiplicity Counting," Los Alamos National Laboratory report LA-13422-M (1998).

[9] Kneissl U., Pitz H.H., and Zilges, "Investigation of Nuclear Structure by Resonance Fluorescence Scattering," Prog. Part. Nuclear Physics, Vol. 37 pp. 349-433, S0146-6410(96)00055-5 (1996).

[10] Lee D.M., Lindquist L.O., "Self-Interrogation of Spent Fuel," Los Alamos National Laboratory Report LA-9494-MS (August 1982).

[11] Menlove, H.O., Beddingfield, D.H., Passive Neutron Reactivity Measurement Technique, Los Alamos National Laboratory document LA-UR-97-2651 (May 1997).

[12] Tobin S.J. , Beddingfield D.H. , Menlove H.O. , and Swinhoe M.T., Non-Proliferation Technology Development Study for UREX, IAEA 
Symposium on International Safeguards: Addressing Verification Challenges, Vienna, Austria, (2006).

[13] Menlove H.O. et al., "A resonance self-indication technique for isotopic assay of fissile materials," Nuclear Applications, 401, Vol. 6, (1969).

[14] LaFleur A.M. et al., "Nondestructive Measurements of Fissile Material Using Self-Indication Neutron Resonance Absorption Densitometry (SINRAD)", $8^{\text {th }}$ International Conference on Facility Operations Safeguards Interface, March 30 - April 4, 2008, Portland

[15] Rudy C., et al.," Determination of Pu in Spent Fuel Assemblies by XRay Fluorescence," Institute of Nuclear Material Management Annual Conference, LA-UR- 05-4283, (2005).

[16] S. J. Tobin, S. F. Demuth, M. L. Fensin, J. S. Hendricks, H. O. Menlove, M. T. Swinhoe. "Determination of Plutonium Content in Spent Fuel with NDA-Why an Integrated Approach?" Institute of Nuclear Material Management $49^{\text {th }}$ Annual Conference LA-UR- 0803763, (2008).

[17] D. B. Pelowitz, J. S. Hendricks, J. W. Durkee, M. R. James, M. L. Fensin, G. W. McKinney, S. G. Mashnik, L. S. Waters, "MCNPX 2.7.A Extensions," Los Alamos National Laboratory Report: LA-UR-0807182 (2008).

[18] B. J. Quiter "Resonance Fluorescence for Material Assay" Proceedings of the $1^{\text {st }}$ ANIMMA Conference, Marseilles, France 2009.
[19] N. P. Sandoval and M. L. Fensin, "Burnup Automation MCNPX File Data Retrieval Tool (BAMF-DRT): Data Extraction and Input File Creation Tool Users Manual," Los Alamos National Laboratory Report: LA-UR-09-01259, Los Alamos, NM (2008)

[20] B. J. Quiter "Resonance Fluorescence for Material Assay" Proceedings of the $1^{\text {st }}$ ANIMMA Conference, Marseilles, France 2009.

[21] M. L. Fensin, S. J. Tobin, N. P. Sandoval, M. T. Swinhoe, H. O. Menlove "A Monte Carlo Based Spent Fuel Analysis Safeguards Strategy Assessment" Proceedings of Global 2009, Paris, France, September 6-11, 2009

[22] S.J. Tobin, M. L. Fensin, B. A. Ludewigt, H. O. Menlove B. J. Quiter, N. P. Sandoval, M. T. Swinhoe, S. J. Thompson "Determining Plutonium Mass in Spent Fuel with Nondestructive Assay Techniques Preliminary Modeling Results Emphasizing Integration among Techniques" Proceedings of Global 2009, Paris, France, September 611,2009

[23] A.M. LaFleur, W.S. Charlton, H.O. Menlove, and M. Swinhoe. “ Development of Self-Interrogation Neutron Resonance Densitometry (SINRD) to Measure the ${ }^{235} \mathrm{U}$ and ${ }^{239} \mathrm{Pu}$ Content in a PWR $17 \times 17$ Spent Fuel Assembly" Proceeding of the $31^{\text {st }}$ ESARDA conference, Vilnius, Lithuania May 26-28, 2009.. 